\title{
Successful Management of Renal Transplant Recipients with Hepatitis C by Direct-Acting Antiviral Therapy: A Report on Three Cases
}

\section{Tamotsu Tojimbara*, Jun Yashima, Shirai Hiroyuki and Satoshi Teraoka}

Department of Transplant Surgery, International University of Health and Welfare, Atami Hospital, Shizuoka, Japan

${ }^{*}$ Corresponding Author: Tamotsu Tojimbara, Department of Transplant Surgery, International University of Health and Welfare, Atami Hospital, Shizuoka, Japan, Tel: +81557819171; E-mail: tojimbara@iuhw.ac.jp

Received date: March 30, 2017; Accepted date: April 27, 2017; Published date: May 02, 2017

Citation: Tojimbara T, Yashima J, Hiroyuki S, Teraoka S (2017) Successful Management of Renal Transplant Recipients with Hepatitis C by DirectActing Antiviral Therapy: A Report on Three Cases. J Clin Exp Nephrol 1: 32. doi: 10.21767/2472-5056.100032

Copyright: (c) 2017 Tojimbara T, et al. This is an open-access article distributed under the terms of the Creative Commons Attribution License, which permits unrestricted use, distribution, and reproduction in any medium, provided the original author and source are credited.

\section{Abstract}

We evaluated the efficacy of direct-acting antiviral (DAA) therapy in the management of renal transplant recipients with hepatitis C virus (HCV) infection.

Methods: We treated two of our renal transplant recipients (Patients 1 and 2) who were HCV-RNA-(genotype 1b) positive with daclatasvir and asunaprevir. Another recipient (Patient 3), who was positive for HCV (genotype 2b), was treated with sofosbuvir and ribavirin. Patient 1 received DAA treatment following unsuccessful pegylated-interferon therapy. Prior to DAA therapy, his HCV-RNA level was $6.0 \mathrm{log}$ $\mathrm{IU} / \mathrm{mL}$. After 8 weeks of treatment, DAA therapy was discontinued due to allograft dysfunction. In Patient 2, HCVRNA level before DAA therapy was $6.9 \log \mathrm{IU} / \mathrm{mL}$. In Patient 3, DAA therapy was initiated 4 months after renal transplantation, when the patient's HCV-RNA level was 7.4 $\log I U / \mathrm{mL}$.

Results: In all cases, HCV-RNA was undetectable within 4 weeks of the initiation of DAA therapy and a sustained virological response was maintained. In Patient 1 , transient deterioration of renal function gradually recovered. Patient 3 developed BK virus nephropathy (BKN) 5 weeks after completion of DAA therapy, although the relationship between DAA and BKN remains unclear.

Conclusion: DAA therapy was successful in the therapeutic management of our three HCV-infected renal transplant patients. Although physicians should be aware of the possibility of complex drug interactions, DAA therapy under such conditions may provide promising short-term outcomes.

Keywords: Renal transplant recipient; Hepatitis C virus; Direct-acting antiviral therapy; BK virus nephropathy

\section{Introduction}

The prevalence of hepatitis $\mathrm{C}$ virus (HCV) is significantly higher in renal transplant recipients than in the general population and is associated with increased morbidity and mortality [1]. In spite of recent therapeutic advances, such as interferon (IFN)-free regimens, the management of $\mathrm{HCV}$ infection continues to be a challenge, especially in patients with renal dysfunction. In recent times, the treatment of HCV infection has been completely revised in order to include new-generation, direct-acting antivirals (DAAs), which have been proven to be highly effective in treating HCV infection in cirrhotic and non-cirrhotic immunecompetent patients [2]. However, DAAs have not been comprehensively tested in renal transplant recipients [3]. Here, we describe three cases of HCV-positive renal transplant recipients who received IFN-free DAA therapy.

\section{Case Reports}

Two of the three cases (Patients 1 and 2) described herein were HCV-RNA-(genotype 1b) positive, whereas the third (Patient 3) was HCV-RNA-(genotype 2b) positive. None of the three patients possessed mutations (L31 and Y93) in the NS5A gene. We treated Patients 1 and 2 with a combination of daclatasvir $(60 \mathrm{mg} /$ day $)$ and asunaprevir $(200 \mathrm{mg} /$ day $)$, and Patient 3 with a combination of sofosbuvir $(400 \mathrm{mg} /$ day) and ribavirin ( $400 \mathrm{mg} /$ day). HCV-RNA titer was assessed using an assay based upon real-time reverse transcription polymerase chain reaction (PCR) (Roche COBAS TaqMan, Roche Diagnostics, Indianapolis, IN). None of the three patients were found to have a hepatitis B coinfection. Although no liver biopsy was performed, the degree of hepatic fibrosis was evaluated macroscopically by ultrasonography and computed tomography, and by analysing data arising from blood counts and blood chemistry.

\section{Case 1}

Patient 1, a 60-year-old man with end-stage renal disease (ESRD) resulting from diabetic nephropathy had previously undergone a living-donor renal transplantation in December 2009, which was followed by hemodialysis for 60 months. He had been diagnosed with chronic hepatitis $C$ (genotype $1 b$ ) over 20 years ago. Twenty-four months after renal transplantation, he was prescribed pegylated-IFN therapy at a dose of $90 \mathrm{mg} /$ week against HCV. However, after 48 weeks, this line of treatment was 
found to be ineffective in achieving a sustained virological response (SVR) and his renal graft function gradually deteriorated, as evidenced by serum creatinine $(\mathrm{Cr})$ levels rising from $1.8 \mathrm{mg} / \mathrm{dL}$ to $2.9 \mathrm{mg} / \mathrm{dL}$. Consequently, in December 2014, the patient was switched to DAA treatment with daclatasvir (60 $\mathrm{mg} /$ day) and asunaprevir (200 mg/day). Prior to DAA therapy, his HCV-RNA level was $6.0 \log \mathrm{IU} / \mathrm{mL}$. Ultrasonography and computed tomography revealed nodular changes on the surface of the liver implicating cirrhotic pattern or severe fibrosis, in addition to a low platelet count $(48 \times 103 / \mu \mathrm{l})$.

Immunosuppressive therapy prescribed to the patient comprised of cyclosporine, mycophenolate mofetil (MMF), and methylprednisolone. Prior to the commencement of DAA therapy, cyclosporine was substituted by tacrolimus. Following 8 weeks of treatment, DAA was discontinued because $\mathrm{Cr}$ level had increased from $2.9 \mathrm{mg} / \mathrm{dL}$ to $4.1 \mathrm{mg} / \mathrm{dL}$ indicating a deterioration in allograft function. The patient's renal function gradually recovered and $\mathrm{Cr}$ level fell to $3.1 \mathrm{mg} / \mathrm{dL}$ once DAA therapy was stopped. However, HCV-RNA titer was undetectable when measured 4 weeks after starting therapy and SVR was maintained at 22 months after the discontinuation of DAA.

\section{Case 2}

Patient 2, a 55-year-old man with ESRD due to diabetic nephropathy had previously received a living-donor renal transplant in October 2007, which was followed by hemodialysis for 55 months. He had been identified as HCV genotype $1 \mathrm{~b}$ positive in 1997 with a high viral titer of $>6.0 \log \mathrm{IU} / \mathrm{mL}$, although his liver function test values were within normal range at the time of transplantation. The patient was immunosuppressed with basiliximab and methylprednisolone during the induction phase and with cyclosporine and MMF for maintenance. In August 2015, 93 months after renal transplantation, the patient was initiated on a 24-week protocol of DAA treatment consisting of daclatasvir (60 mg/day) and asunaprevir (200 mg/day). No serious complications were reported during this regimen with the exception of general fatigue at the beginning of therapy. The patient's HCV-RNA level was $6.9 \log \mathrm{IU} / \mathrm{mL}$ before initiating DAA therapy and was undetectable after 4 weeks of therapy. SVR was maintained at 11 months after the completion of DAA therapy.

\section{Case 3}

Patient 3, a 46-year-old man with ESRD as a complication of chronic glomerulonephritis had undergone deceased-donor renal transplant in December 2015, followed by hemodialysis for 252 months. He had been diagnosed with chronic hepatitis $C$ (genotype 2b) in 1997 although his liver function test values were within normal range at the time of transplantation. Basiliximab and methylprednisolone were used for immunosuppression during the induction phase and tacrolimus and MMF were administered for maintenance. The patient's DAA treatment was initiated 4 months after transplantation, when his HCV-RNA level was $7.4 \log \mathrm{IU} / \mathrm{mL}$, and the prescribed agents were sofosbuvir ( $400 \mathrm{mg} /$ day) and a reduced dose of ribavirin (400 mg/day). His renal graft function was stable before the initiation of DAA therapy with serum $\mathrm{Cr}$ levels of 1.2-1.4 $\mathrm{mg} / \mathrm{dL}$; these levels were maintained until the completion of the therapy.

Erythropoietin (darbepoetin alfa) was used prophylactically against ribavirin-induced anemia prior to the commencement of DAA therapy. No serious complications were reported during the 12-week regimen with the exception of anaemia which required additional erythropoietin after the completion of therapy. After 4 weeks of DAA treatment, the HCV-RNA titer had become undetectable and SVR at 12 weeks after the completion of therapy was achieved. Five weeks after the completion of DAA therapy, the patient's renal graft function deteriorated $(\mathrm{Cr}$ level increased from $1.4 \mathrm{mg} / \mathrm{dL}$ to $2.2 \mathrm{mg} / \mathrm{dL}$ ). Allograft biopsy at that time revealed $B K$ virus nephropathy (BKN) stage $B$ without evidence of acute rejection [4]. At the same time, Decoy cells were detected in the patient's urine samples. Furthermore, BK virus-DNA was detected in both plasma ( $>4 \log$ copies $/ \mathrm{mL}$ ) and urine ( $>7$ log copies $/ \mathrm{mL}$ ). Despite the standard of care for the treatment of BKN, including immunosuppression reduction, intravenous immunoglobulin (IVIG), tacrolimus conversion to cyclosporin, MMF conversion to everolimus, the patient continued to experience persistent BKN and his $\mathrm{Cr}$ level increased to $3.3 \mathrm{mg} / \mathrm{dL}$. Leflunomide was used as an adjuvant therapy at a dose of $20 \mathrm{mg} /$ day following a reduced loading dose of $60 \mathrm{mg}$ for 5 days. After 8 weeks of leflunomide administration with standard care, the patient cleared his BK viremia, whereas BK virus persisted in his urine. His renal graft function gradually recovered and $\mathrm{Cr}$ level fell to $2.2 \mathrm{mg} / \mathrm{dL}$ from $3.3 \mathrm{mg} / \mathrm{dL}$, although his $\mathrm{Cr}$ level did not returned to baseline. SVR was maintained at 8 months after the completion of DAA therapy.

Patient and transplant characteristics are summarized in Table 1. Treatment characteristics at the time of DAA initiation, along with treatment outcomes, are shown in Table 2. HCV-RNA was undetectable in all patients within 4 weeks of the initiation of DAA therapy. In every patient, including Patient 1 whose treatment was discontinued 8 weeks after initiation, SVR was achieved until the final visit to the outpatient clinic (minimum follow-up was 8 months). Although the renal allograft function of Patient 1 deteriorated 8 weeks after DAA initiation, it returned to baseline level when therapy was discontinued.

Table 1: Patient and transplant characteristics. CNI: Calcineurin inhibitor; MMF: Mycophenolate mofetil; M: Male; Tac: Tacrolimus; CsA: Cyclosporine.

\begin{tabular}{|l|l|l|l|l|l|l|l|l|}
\hline Patient & $\begin{array}{l}\text { Age } \\
\text { (yr) }\end{array}$ & Sex & $\begin{array}{l}\text { Pretransplant dialysis } \\
\text { interval (mo) }\end{array}$ & $\begin{array}{l}\text { HCV positive } \\
\text { donor }\end{array}$ & Induction & CNI & $\begin{array}{l}\text { MMF dose } \\
\text { (mg) }\end{array}$ & Prednisolone (mg) \\
\hline 1 & 60 & M & 60 & - & basiliximab & Tac & $500 / 500$ & 4 \\
\hline
\end{tabular}




\begin{tabular}{|l|l|l|l|l|l|l|l|l|}
\hline 2 & 55 & $\mathrm{M}$ & 55 & - & basiliximab & CsA & $500 / 500$ & - \\
\hline 3 & 46 & $\mathrm{M}$ & 252 & - & basiliximab & Tac & $500 / 500$ & - \\
\hline
\end{tabular}

Table 2: Hepatitis $C$ virus infection and treatment characteristics at the time of direct-acting antiviral initiation and outcome. IFN: Interferon; CT: Computed tomography; DAA: Direct-acting antiviral; RBV: Ribavirin; SVR12: Sustained virological response at 12 weeks after completing DAA therapy; DAC: Daclatasvir; ASN: Asunaprevir; SOF: Sofosbuvir.

\begin{tabular}{|c|c|c|c|c|c|c|c|c|c|c|c|}
\hline Patient & Genotype & $\begin{array}{l}\text { Viral } \\
\text { load } \\
\text { (log } \\
\text { IU } / \mathrm{mL} \text { ) }\end{array}$ & $\begin{array}{l}\text { Prio } \\
r \\
\text { IFN }\end{array}$ & $\begin{array}{l}\text { Ultrasonogram } \\
\text { and/or CT }\end{array}$ & $\begin{array}{l}\text { Platelet } \\
\text { s }\left(\times 10^{3} /\right. \\
\mu \mathrm{L})\end{array}$ & $\begin{array}{l}\text { Albumin } \\
\text { (g/dl) }\end{array}$ & $\begin{array}{l}\text { DAA } \\
\text { regimen }\end{array}$ & $\begin{array}{l}\text { RBV } \\
\text { dose }\end{array}$ & $\begin{array}{l}\text { Post- } \\
\text { transplant } \\
\text { (Mo) }\end{array}$ & $\begin{array}{l}\text { Rapid } \\
\text { virologial } \\
\text { response }\end{array}$ & $\begin{array}{l}\text { SVR1 } \\
2\end{array}$ \\
\hline 1 & $1 \mathrm{~b}$ & 6.0 & Yes & cirrhotic pattern & 48 & 4.1 & $\begin{array}{l}\text { DAC + } \\
\text { ASN }\end{array}$ & - & 60 & Yes & Yes \\
\hline 2 & $1 \mathrm{~b}$ & 6.9 & - & - & 119 & 4.1 & $\begin{array}{l}\text { DAC+ } \\
\text { ASN }\end{array}$ & - & 93 & Yes & Yes \\
\hline 3 & $2 \mathrm{~b}$ & 7.4 & - & dull liver edge & 132 & 4.3 & SOF & $\begin{array}{l}400 m \\
g\end{array}$ & 4 & Yes & Yes \\
\hline
\end{tabular}

\section{Results}

In renal transplant patients, the presence of HCV can result in numerous complications such as reduced survival of patients and renal allografts, increased liver fibrosis and infection rates, glomerulonephritis, new-onset diabetes mellitus and cardiovascular disease [1]. Although IFN-based regimens have been considered as pivotal components of HCV treatment, some reports argue that the effectiveness of IFN is limited by its relatively low efficacy and poor tolerability in patients with ESRD [5]. Furthermore, IFN-based anti-HCV therapy is somewhat contraindicated in renal transplant cases because of an increased risk of acute rejection because of the immunostimulatory properties of IFN [6].

The recently-approved DAAs are small-molecule inhibitors of the HCV life cycle, designed to target non-structural viral proteins such as NS3, NS4A, NS4B, NS5A, and NS5B. Genotypic coverage varies among these DAA agents, and studies have shown that the use of a combined regimen of these agents for 12 weeks could achieve a SVR in excess of $90 \%$ in a treatmentnaïve general population [7]. Hence, an appropriate combination of DAAs has the potential to be highly effective in the treatment of HCV infection. However, initial preclinical and clinical studies on DAAs have excluded patients receiving renal transplants, or those on dialysis, as well as patients with a glomerular filtration rate (GFR) of $<30 \mathrm{ml} / \mathrm{min}$. Thus, there are only a few studies which have evaluated the efficacy of DAAs and provide guidance in relation to their use for renal transplant patients [8].

Daclatasvir is a pan-genotypic NS5A inhibitor which does not require dose adjustment when co-administered with calcineurin inhibitors such as tacrolimus or cyclosporine [9]. A combination of daclatasvir with a protease inhibitor, asunaprevir, against HCV genotype $1 \mathrm{~b}$ has been approved for use in Japan and was prescribed to Patients 1 and 2 in our present case study.

Sofosbuvir is excreted via the kidneys and previous pharmacokinetic studies recommend dose adjustment for patients with a GFR of $<30 \mathrm{~mL} / \mathrm{min}$ and hemodialysis patients. In Patient 3, we did not reduce the dose of sofosbuvir on account of acceptable renal allograft function. Instead, the dose of ribavirin was reduced to $400 \mathrm{mg} /$ day and erythropoietin was added to the regimen as a prophylactic to counter any ensuing anemia. Despite this precaution, the patient required additional erythropoietin for anemia, which was sustained even after the completion of therapy. Unfortunately, Patient 3 developed BKN 5 weeks after the completion of DAA therapy with sofosbuvir and ribavirin. BKN is estimated to occur in $5 \%-10 \%$ of renal transplant recipients with reports of graft loss in $10 \%-80 \%$ of such patients. Despite the standard of care for treatment of BKN including immunosuppression reduction, conversion from tacrolimus to cyclosporin, and conversion from MMF to everolimus, some patients continue to experience persistent BKN. Several adjuvant therapies, such as leflunomide, cidofovir, and IVIG, have been tried; however, guidelines for their use are not well established [4]. We chose leflunomide and IVIG as adjuvant therapies because cidofovir was not approved in Japan. Eight weeks after treatment for BKN including leflunomide, Patient 3 cleared his BK viremia. His renal function gradually recovered and $\mathrm{Cr}$ level fell to $2.2 \mathrm{mg} / \mathrm{dL}$ from $3.3 \mathrm{mg} / \mathrm{dL}$, although $\mathrm{Cr}$ level did not return to baseline.

To our knowledge, there are no previously published reports indicating a potential association between DAA therapy and activation of the BK virus. In transplant recipients, however, DAA might influence the immune response and viral replication, although no significant dosing interaction between DAA and tacrolimus was observed in Patient 3 in our present study (data not shown).

In our three patients, we observed a rapid virological response to DAA therapy, defined by undetectable viremia following 4 weeks of initiating therapy. We also demonstrated a SVR of $100 \%$ in all three patients, which was maintained until the final visit to the outpatient clinic. Moreover, DAA therapy was well-tolerated, with the exception of Patient 1 , who had to discontinue therapy. However, it must be noted that in this patient, graft dysfunction had already been reported earlier 
following pegylated-IFN therapy for 48 weeks. We could speculate that the prior use of pegylated-IFN may have induced acute or chronic rejection, although we could not confirm this by biopsy because the patient also presented with thrombocytopenia. Furthermore, there was no episode of acute rejection in the other two patients while on DAA treatment. In our three cases, we could not confirm that DAAs had a significant effect upon blood levels of calcineurin inhibitors, although some reports have suggested an interaction between DAAs and calcineurin inhibitors [8].

In conclusion, DAA therapy, using a combination of either daclatasvir and asunaprevir, or sofosbuvir and ribavirin, was successful in the clinical management of our three HCV-positive renal transplant patients. These results show the potential benefits of DAA under such conditions and indicate promising short-term outcomes. However, physicians should be aware of these advantages with a caveat of possible drug interactions and other undesirable side effects of DAA. Hence, further studies are now needed to assess the long-term effects of DAA therapy upon patient and allograft survival in HCV-positive renal transplant cases.

\section{References}

1. Baid-Agrawal S, Pascual M, Moradpour D, Frei U, Tolkoff-Rubin $\mathrm{N}$ (2008) Hepatitis C virus infection in haemodialysis and kidney transplant patients. Rev Med Virol 18: 97-115.

2. Sulkowski MS, Gardiner DF, Rodriguez-Torres M (2014) Daclatasvir plus sofosbuvir for previously treated or untreated chronic HCV infection. N Engl J Med 370: 211-221.
3. Baid-Agrawal S, Pascual $M$, Moradpour $D$, Somasundaram $R$, Muche M (2014) Hepatitis C virus infection and kidney transplantation in 2014: What's new? Am J Transplant 14: 2206-2220.

4. Hirsch HH, Randhawa P (2013) AST Infectious Disease Community of Practice. BK Polyomavirus in Solid Organ Transplantation, Am J Transplant 13 (s4): 179-188.

5. Prabhu RA, Nair S, Pai G, Reddy NP, Suvarna D (2015) Interventions for dialysis patients with hepatitis C virus (HCV) infection. Chochrane Databese Syst Rev 8: CD007003.

6. Rostaing L, Izopet J, Baron E, Duffaut M, Puel J, et al. (1995) Treatment of chronic hepatitis $C$ with recombinant interferon alpha in kidney transplant recipients. Transplantation 59: 1426-1431.

7. Lawitz E, Sulkowitz MS, Ghalib R (2014) Simeprevir plus sofosbuvir, with or without ribavirin, to treat chronic infection with hepatitis $C$ virus genotype 1 in non-responders to pegylated interferon and ribavirin and treatment-naive patients: The COSMOS randomized study. Lancet 384: 1756-1765.

8. Sawinski D, Kaur N, Ajeti A (2016) Successful treatment of hepatitis $C$ in renal transplant recipients with direct-acting antiviral agents. Am J Transplant 16: 1588-1595.

9. Tischer S, Fontana RJ (2014) Drug-drug interactions with oral anti$\mathrm{HCV}$ agents and idiosyncratic hepatotoxicity in the liver transplant setting. J Hepatol 60: 872-884. 